TITLE:

\title{
Research at Bossou
}

\author{
$\operatorname{AUTHOR}(\mathrm{S})$ :
}

Sugiyama, Yukimaru

CITATION:

Sugiyama, Yukimaru. Research at Bossou. Pan Africa News 1994, 1(1): 23

ISSUE DATE:

1994

URL:

http://hdl.handle.net/2433/143539

RIGHT:

Copyright (C) Pan Africa News. 


\section{Research at Bossou}

After a short study without individual identification in 1975 all chimpanzees at Bossou have been identified and observed every year (with exceptions in 1978, 1981 and 1984). Fortunately, the group has not suffered from poaching from the beginning of the study.

We have, however, seen the effects of the extreme upheaval in Liberia that began with a rebellion against the government in 1989 and continues to the present time. Liberia lies adjacent to Guinea, and the frontier is less than 10 km from our study site at Bossou. Beginning in early 1990, a large number of Liberian refugees began streaming into Guinea. Many of them did not understand the local language, Manon, nor the official or "traditional" rules of Bossou. They invaded the forest, and began to cut down trees for building materials and cultivation space. Frightened by the noisy disturbance, the chimpanzees became very shy and reluctant to forage in those areas. As the population of the vilage of Bossou almost doubled from the previous figure of 1600 persons, the number of the chimpanzee study group decreased from 20 to 16.

The Guinean government responded to the crisis in a number of ways. The area of the reserve was enlarged to 12 $\mathrm{km}^{2}$, and a border was drawn enclosing the $6 \mathrm{~km}^{2}$ core area of the chimpanzees. The planted bamboo which marks the border, though, has sometimes been destroyed by uninformed people from the village who cut it for their own use. The government also named our local assistants as forest guards, but problems such as lodging and salaries remain unresolved, and the area of deforestation continues to expand.

The Japanese government has financed the construction of the "Bossou Institute of Environmental Research", to be run by the Directeur National de la Recherche Scientifique et Technique, a branch of the government of the Republic of Guinea. The Institute, when finished, will serve as the base for the local research and conservation effort. Construction work, however, proceeds slowly. Donations to help equip the Institute would of course be highly appreciated!

Since 1987 our research station in the village has been a rather simple and ordinary local house. From this house, 
when the chimpanzees visit the central part of their core area, we can hear their morning and late-night calls. Daily meals of local foods are prepared by our cook, and of course locally made palm wine is readily available!

Throughout each individual field season we rarely need to go to town. After a long day spent in the field, we enjoy cold baths by moonlight (no electricity is available except to power the small generator used to charge batteries, and anyway petrol is filthy and expensive and a nuisance), and before we retire check beneath the bed for poisonous snakes which sometimes find their way inside the house. Although many local diseases "welcome" us each time, we think life at Bossou is quite comfortable, though perhaps it wouldn't be for more "civilized"scientists!

Field studies are going quite well. For the purpose of some experimental work which we began in 1990, we give the chimps 10 bananas or oranges per day per group; prior to this they had not received food from us.

We are now training a few village youths to help with the survey; one of our assistants is the current V.I.P of the village, and he and a few others are getting a bit old!

Yukimaru Sugiyama, Kyoto University Primate Research Institute

\section{The Bossoun Chmpamze. Research Profect}

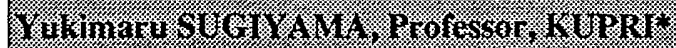

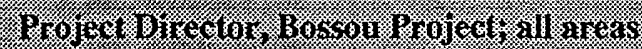

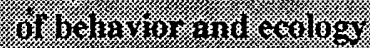

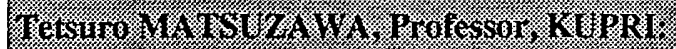

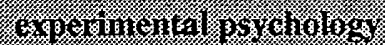

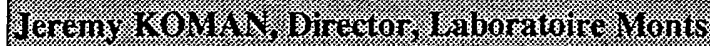

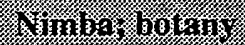

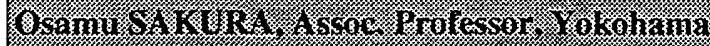

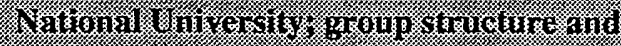

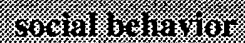

Y.

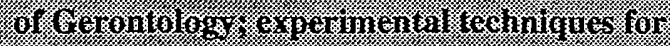

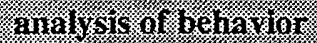

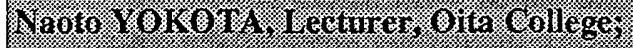

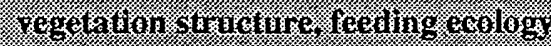

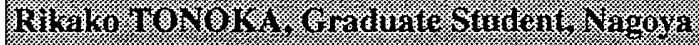

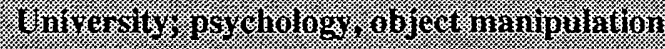

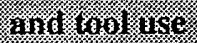

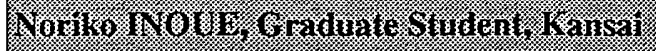

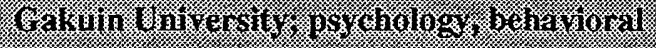

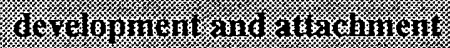

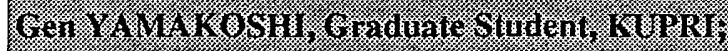

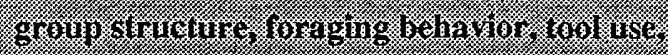

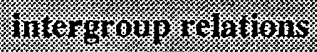

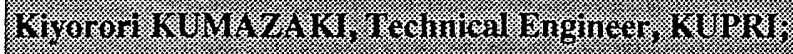

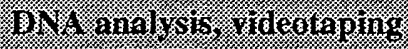

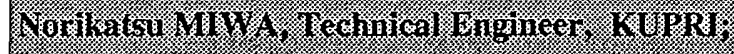

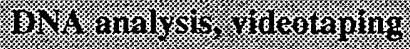

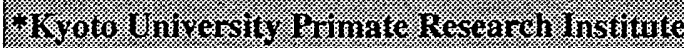

